\title{
Spinal Epidural Venous Angioma Presenting Symtomps of Lumbar Disc Herniation: A Case Report
}

\author{
Eyup BAYKARA ${ }^{1}$, Mustafa KORUCU², Mevci OZDEMIR ${ }^{3}$, Sevki GOK ${ }^{4}$ \\ ${ }^{1}$ Kars Harakani State Hospital, Department of Neurosurgery, Kars, Turkey \\ ${ }^{2}$ Viransehir State Hospital, Department of Neurosurgery, Sanliurfa, Turkey \\ ${ }^{3}$ Private Denizli Cerrahi Hospital, Department of Neurosurgery, Denizli, Turkey \\ ${ }^{4}$ Medical Park Silivri Hospital, Department of Neurosurgery, Istanbul, Turkey \\ Corresponding author: Eyup BAYKARA dr.eyupbaykara@hotmail.com
}

\section{ABSTRACT}

Spinal epidural venous angiomas are extremely rare. We report the case of a 60-year-old man who presented with disc herniation symptoms, complaining of pain in his left leg and numbness, especially at the base of the knee. On physical examination, the Lasègue test was positive at 45 degrees on the left side and no neurological deficit was detected on the lower extremity. Contrast enhanced magnetic resonance imaging revealed a lesion in the left $\mathrm{S} 1$ neural foramen, which was initially evaluated as a schwannoma. However, after the lesion was totally excised, it was pathologically identified as a venous angioma. Here, the clinical presentation, management, and surgical, radiological, and pathological features are discussed.

KEYWORDS: Spinal epidural venous angioma, Lasègue test, Disc herniation, Lumbar spine

\section{INTRODUCTION}

S pinal vascular malformations are classified by histological type and location (2,8). They are heterogeneous, manifesting as a wide clinical spectrum of symptoms that range from chronic, progressive neurological deficits to acute hemorrhages with an insidious presentation, and they account for $3 \%-12 \%$ of spinal space-occupying lesions (6). Spinal angiomas include capillary telangiectasias (which can be extradural, intradural or, rarely, intramedullar), cavernomas (mainly observed in vertebral bodies), and venous angiomas (mainly located in vertebral bodies and in the extradural space). Here, we report the case of a patient who presented with disc herniation symptoms and was ultimately diagnosed with venous angioma.

\section{CASE REPORT}

A 60-year-old man presented with left-sided leg pain and numbness, especially at the base of the knee, which had persisted for 3-4 months. He was referred to our institution with a diagnosis of left L5-S1 root schwannoma. We acquired new images by magnetic resonance imaging (MRI) in our institute, and these revealed a lesion that was hypointense on both T1- and T2-weighted images and was compressing the root. Contrast-enhanced MRI showed heterogeneously marked enhancement after gadolinium administration (Figures 1-4). In the physical examination, the Lasègue test was positive at 45 degrees on the left side, and no neurological deficit was detected in his lower extremity.

A L5-S1 left hemilaminectomy using a posterior approach was performed. After the retraction of the root under microscopic magnification, high vascularity and a dark red epidural mass were observed on the left side of the root. The lesion was separated from the dura by sharp boundaries. Following bipolar coagulation around the lesion, it was dissected from the dura and totally excised. The pathological examination showed a proliferation of dilated thin-wall vein structures and with special orcein dyeing, revealing no elastic fiber in the vein walls. The structures were positive for CD31, but glial fibrillar

$\begin{array}{llll}\text { Eyup BAYKARA } & \text { (D): 0000-0001-9984-0322 } & \text { Mevci OZDEMIR } & \text { (D): 0000-0002-2816-0722 } \\ \text { Mustafa KORUCU } & \text { (D): 0000-0003-1863-7248 } & \text { Sevki GOK } & \text { (D): 0000-0002-9361-8787 }\end{array}$ 

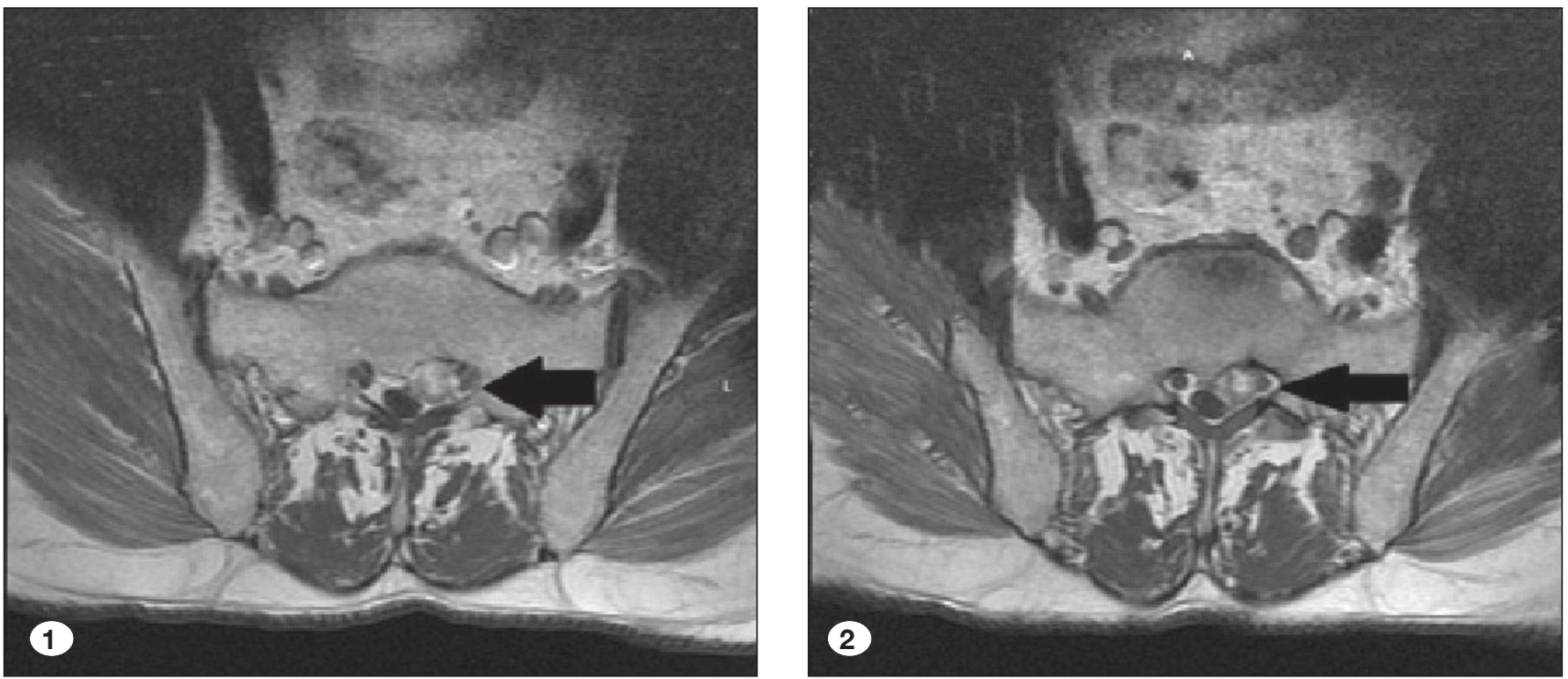

Figure 1-2: Contrast-enhanced axial T1 weighted MRI illustrating heterogeneously marked enhancement of the lesion.

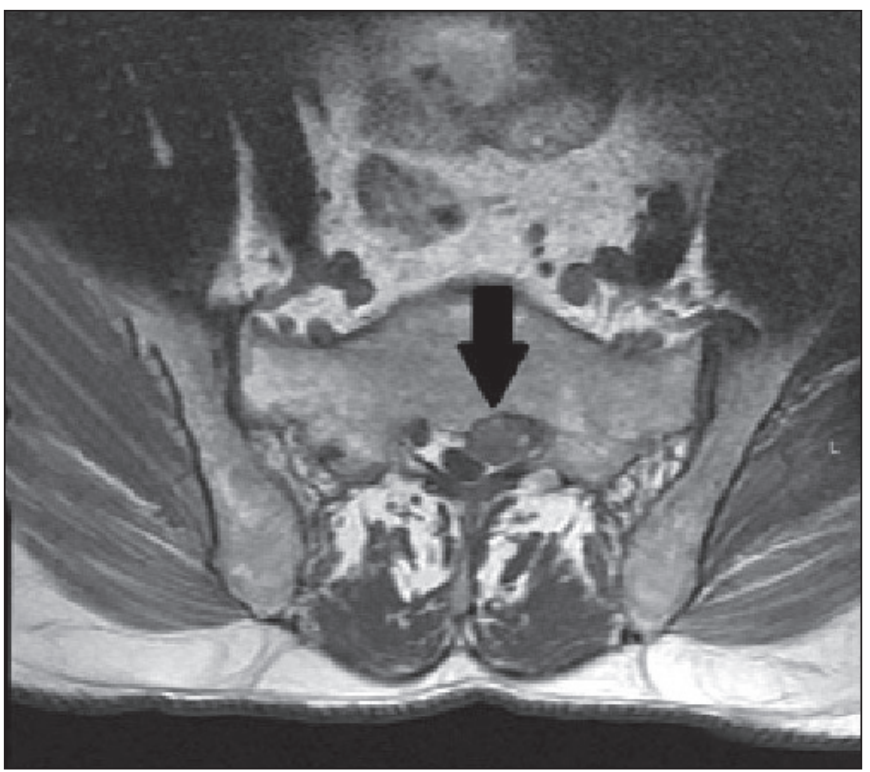

Figure 3: Axial T1 weighted MRI showing hypointense signal at the L5-S1 level of the left root.

acidic protein and S-100 protein were not detected (Figure 5, 6). The final diagnosis was venous angioma.

The patient was mobile 6 hours after the surgery, and by the third day postoperatively, his pain had gone, although some numbness at the base of the knee remained. This had cleared by the 6-month follow-up, and no recurrence was observed on the control MRI.

\section{DISCUSSION}

Extradural angiomas, which account for $15 \%-20 \%$ of all spinal vascular anomalies and for approximately $4.7 \%$ of all spinal space-occupying lesions, are rarely isolated (6). Their feeding

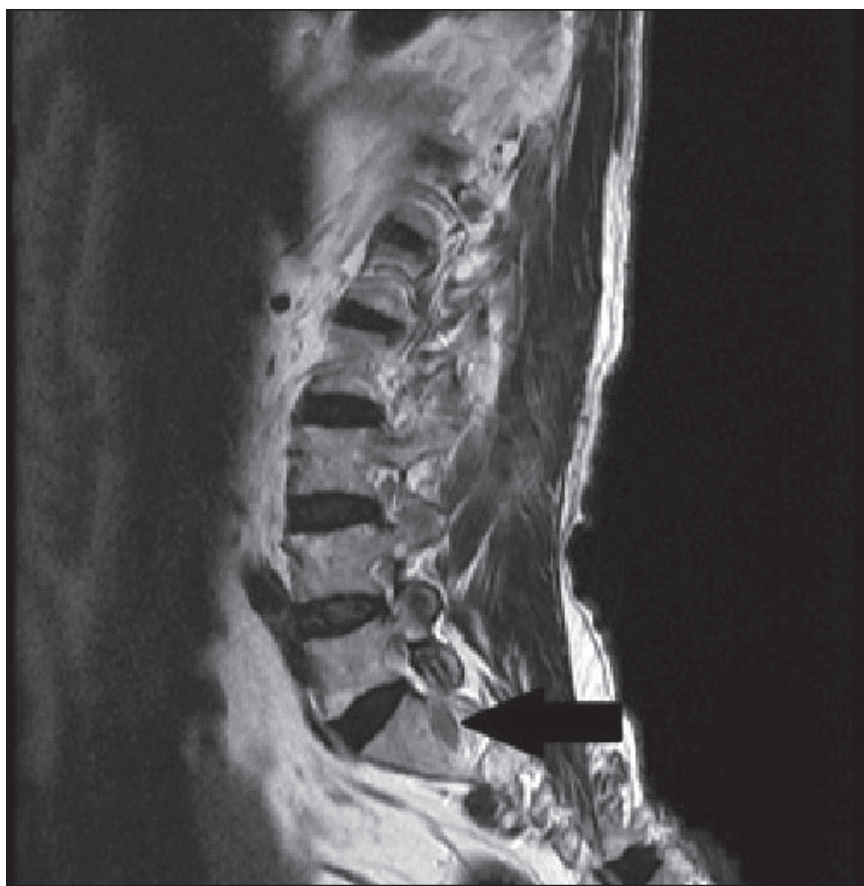

Figure 4: Sagittal T2 weighted MRI showing hypointense signal.

vessels usually exhibit no communication with the spinal cord arteries; therefore, these malformations play no part in the vascular supply to the cord (11), although a spinal epidural angioma draining into intrathecal veins has been reported (7). The functional anatomic separation of extradural angiomas, the majority of which are exclusively extradural, and those in the subdural space and spinal cord should be considered in angiographic diagnosis and treatment.

Venous malformations, described as varicose veins or racemose varicose veins, are composed entirely of veins, either 


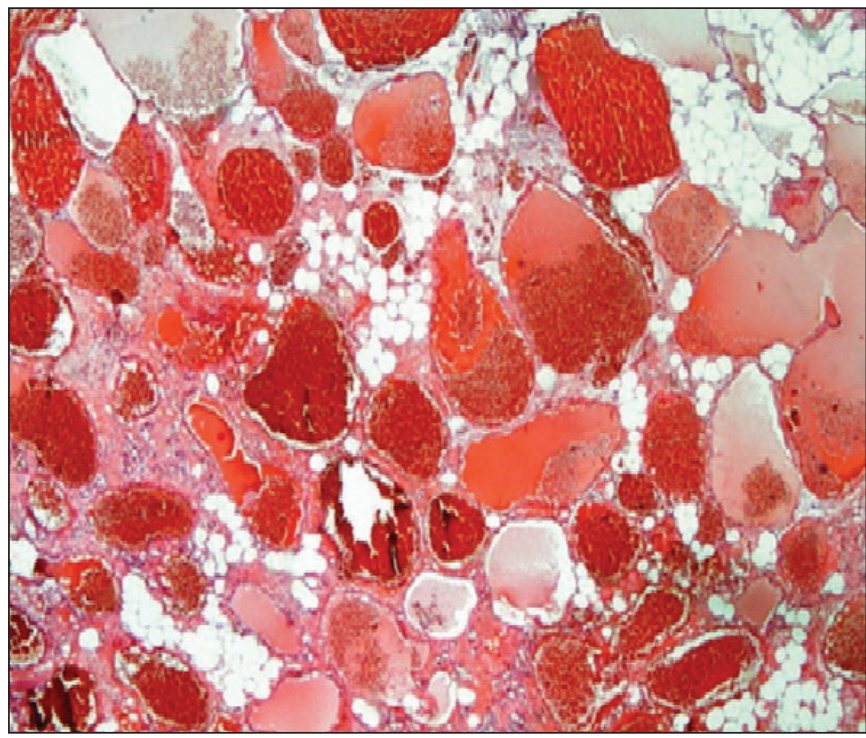

Figure 5: Different diamater and dimention, thin walled, muscle layer is not selected on the walls, CD31 lined with endothelial cells, congested irregular cystic enlarged venous vessels structures (x40 magnification).

dilated venules with one or more draining pedicles, or enlarged veins.

Histologically, venous angiomas show significant hyaline and collagenous thickening in the vessel wall. Thrombosis and inflammation of the various veins can be seen with immunohistochemical analysis revealing surface-lining epithelial cells positive for CD31 (12). Racemose venous angiomas are located in the extradural space. However, for the majority of intradural vascular anomalies that were previously classified as spinal varices, spinal varicosis, or racemose venous angiomas, arterial feeders observed on spinal angiography provide a definitive proof that these are arteriovenous angiomas (2). The in vivo separation of arteries and veins during surgery can be difficult because of the slowing of the circulation, darkercolored vessels, and partial thrombosis giving the impression of a venous origin (6). The histologic distinction between arterial and venous channels may be virtually impossible because of the severe structural abnormalities of the vessel walls.

Extradural spinal angiomas are most commonly observed in the dorsal and lumbar regions with solitary forms located particularly in the lower lumbar and lumbosacral regions (9). Even with angiography and MRI, the clinical diagnosis of extradural and intradural angiomas remains difficult $(1,3,4,5,10,13,14)$. Extradural angiomas are most often confused with disc hernias and spinal tumors (3). In our case, both diagnoses were consistent with the MRI findings.

Pain is always experienced with extradural angiomas (13), and local and nervous root pain can aid the diagnosis. It was remarkable that our patient experienced no symptom other than pain and numbness. Angiography provides the best information about the size and extent of the malformation, revealing the nourishing and draining vessels (14). However, spinal angiography was not performed in the present case

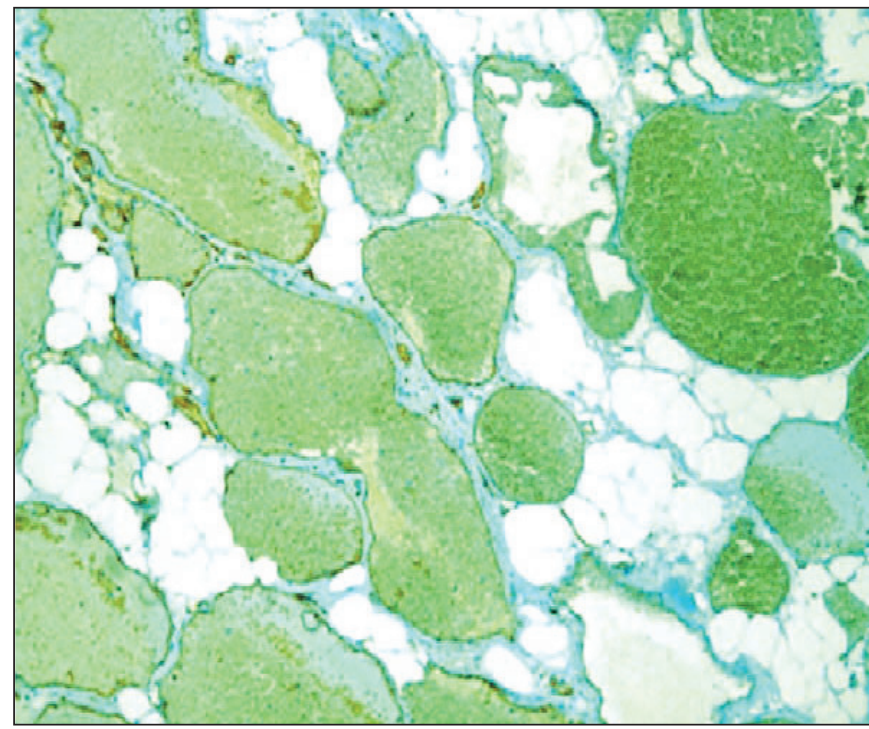

Figure 6: Immunohistochemical examination of CD31 positivity (x100 magnification).

because the possibility of spinal extradural angioma was not considered in the preoperative period. The MRI features are variable and may result in a false diagnosis. The lesions can show irregularly heterogeneous or homogeneous enhancement after gadolinium administration with the tumor borders sharply separated from the normal tissue. The MRI findings may interfere with cystic lesions and tumors (10). In our case, the MRI findings seemed to indicate a schwannoma. The diagnosis of spinal extradural angioma requires both surgical vision and pathological examination.

Venous angiomas are considered to be pathologically benign lesions $(1,5)$. They are well demarcated; therefore, total resection is possible with standard microsurgical techniques. They can adhere to the dura or root but dissection is possible by bipolar coagulation. Surgery has a good clinical outcome. In our case, the postoperative follow-up found no recurrence on the control MRI.

\section{CONCLUSION}

Spinal epidural venous angiomas are rare lesions and are difficult to diagnose preoperatively. On MRI, they can be easily misdiagnosed as tumors, hematomas, or synovial cysts. Surgical resection is essential for the definitive diagnosis and to prevent further neurological symptoms or myelopathy.

\section{- REFERENCES}

1. Aoki R, Srivatanakul K: Developmental venous anomaly: Benign or not benign. Neurol Med Chir 56: 534-543, 2016

2. Badejo L, Sangalang VE: Vascular malformations of the spinal cord (angiodysgenetic myelomalacia): A critique on its pathogenesis. Surg Neurol 11:101-106, 1979 
3. Bursalı A, Akyoldas G, Guvenal AB, Yaman O: Lumbar epidural varix mimicking disc herniation. J Korean Neurosurg Soc 59:410-413, 2016

4. Cho WS, Kim KJ, Kwon OK, Kim CH, Kim J, Han MH, Chung CK: Clinical features and treatment outcomes of the spinal arteriovenous fistulas and malformations. J Neurosurg Spine 19:207-216, 2013

5. Gembruch O, Deuschl C, Teuber Hanselmann S, Schoemberg T, Ozkan N: Thoracic intraspinal venous angioma mimicking a schwannoma: A case report. Open J Clin Med Case Rep 2: 1039-1090, 2016

6. Jellinger $\mathrm{K}$ : Vascular malformations of the central nervous system: A morphological overview. Neurosurg Rev 9:177-216, 1986

7. Kendall BE, Logue V: Spinal epidural angiomatous malformations draining into intrathecal veins. Neuroradiology 13:181-189, 1977

8. Logue V: Angiomas of the spinal cord: Review of the pathogenesis, clinical features, and results of surgery. $J$ Neurol Neurosurg Psychiatry 42:1-11, 1979

9. Mahmoud Reza K, Kazem A, Abbas A: Solitary spinal epidural cavernous angioma: Report of nine surgically treated cases and review of the literature. Eur Spine J 22:542-547, 2013
10. Mascalchi M, Quilici N, Ferrito G, Mangiafico S, Scazzeri F, Torselli P, Petruzzi P, Cosottini M, Tessa C, Bartolozzi C: Identification of the feeding arteries of spinal vascular lesions via phase-contrast MR angiography with three-dimensional acquisition and phase display. AJNR Am J Neuroradiol 18: 351-358, 1997

11. Miyasaka K, Asano T, Ushikoshi S, Hida K, Koyanagı I: Vascular anatomy of the spinal cord and classification of spinal arteriovenous malformations. Interv Neuroradiol 6:195198, 2000

12. Nishimura $Y$, Hara M, Natsume A, Nakajima $Y$, Fukuyama R, Wakabayashi T, Ginsberg HJ: Spinal intradural cystic venous angioma originating from a nerve root in the cauda equina. $J$ Neurosurg Spine 19:716-720, 2013

13. Sanghvi D, Munshi M, Kulkarni B, Kumar A: Dorsal spinal epidural cavernous hemangioma. J Craniovertebr Junction Spine 1:122-125, 2010

14. Wu L, Yang T, Deng X, Yang C, Xu Y: Spinal epidural venous angioma: A case report and review of the literature. Childs Nerv Syst 30:1601-1605, 2014 